\title{
FROM ACADEMIC TO VOCATIONAL: THE REBRANDING OF TEXTILES STUDIES IN MALTA
}

\author{
L. Portelli \\ University of Malta (MALTA)
}

\begin{abstract}
The Ministry of Education and Employment in Malta recently launched a policy to introduce vocational education in secondary schools. The policy documents Learning Outcomes Framework (2015) and My Journey - Achieving through different paths (2016) brought about very significant reforms in the structure of the Maltese educational system. The policy in the latter document aimed to facilitate the introduction of a more equitable quality education within secondary schools. As from 2019, this new proposed model shall offer applied and vocational learning programmes as optional subjects alongside the compulsory core subjects, with the intention of enabling students to reach their full potential. This reform required considerable investment in preparation for the implementation phase. This paper presents a case study of Textiles Studies, an academic subject being phased out from the secondary school curriculum but which shall be introduced as a vocational subject under the name of Textiles and Fashion. It will form part of a group of eleven Vocational Education and Training (VET) subject-areas which shall all be offered as from the scholastic year 2019-20. The paper shall delve into the challenges faced during the planning and preparatory stages, before the subject is actually introduced in schools. It shall highlight the rationale behind the shift of the subject from the academic to the vocational domain, outline the designing of the learning outcomes and discuss issues related to the training and retraining of the subject's teachers. It will also provide a hypothesis, based on the subject's past curriculum history, on how the rebranding process will impact the status of the subject in schools and affect the immediate stakeholders, i.e. students and teachers.
\end{abstract}

Keywords: Vocational Education, Textiles Studies, Educational Policies, Vocational Training.

\section{INTRODUCTION}

These past four decades saw massive reforms in the Maltese education system. Substantial innovations have been introduced to improve the quality of education in order to compare well with other international institutions. From 2014, new policies implemented by the Ministry of Education had a direct impact on the future of Textiles Studies, a school subject which has a long history dating back to the mid-1800s (Portelli, 1996, 2009). Currently, Textiles Studies is being phased out from the secondary school curriculum to be introduced as a vocational subject under the name of Textiles and Fashion. It will form part of a group of nine Vocational Education and Training (VET) subject-areas four of which shall be offered as from the scholastic year 2019-20. The paper shall delve into the challenges faced during the planning and preparatory stages of this transition, before the subject is actually introduced in schools. It shall highlight the rationale behind the shift of the subject from the academic to the vocational domain and discuss issues related to the training and retraining of the subject's teachers. It will also provide a hypothesis, based on the subject's past curriculum history, on how the rebranding process will impact the status of the subject in schools and affect the immediate stakeholders, i.e. students and teachers.

\section{ACADEMIC OR VOCATIONAL: A HISTORICAL CONTEXT}

In 19th century Britain, Needlework was considered as the 'mother of the domestic arts' (Yoxall, 1965, p. 7). It was one of the first subjects specifically taught to girls in British schools. The importance of Needlework as a school subject in Britain extended to Malta, which was a British colony from 1800 1964. As in the mother country, Needlework was considered important for the improvement of the general conditions of society (Portelli, 2009). The subject was taught to females of the lower-classes in order to instil a sense of thrift and domesticity, as, what they learnt could earn them a living. Sewing and needlework were not just learnt at school, most girls learnt these crafts from their mothers and relatives. By 1892, needlework was described as 'a most important branch of female education' in the elementary school (Caruana, 1892, p. 4, cited in Portelli, 2016). The subject was seen as a means of developing girls' skills that could be utilised at home. 
During the 20th century, the popularity of Needlework increased. It was taught in elementary schools for girls and in most girls' secondary schools in Malta and Gozo. It was also taught in Handwork Schools that were established after 1935 (Portelli, 2016). After the Second World War, the subject flourished, especially when new secondary schools were built and most schools were equipped with Needlework rooms. The education authorities invested heavily in the subject, especially after obtaining funds from foreign institutions such as FAO and UNCEF. The popularity of the subject reached its peak when the first Technical School for girls, Maria Assumpta Girls' Secondary School Technical School, was established in 1959, since it aimed at promoting practical subjects. Needlework was the second most popular subject after Shorthand and Typing, possibly due to its popularity at primary level. Parents and students appreciated the usefulness of the subject, which was seen as a way to save money by sewing one's own clothes. At the time, it was customary for households to own a sewing machine, and for at least one family member to have good sewing skills. In those years, the popularity of Needlework was reflected in the numerous evening courses in Dress-Cutting and Tailoring held all over Malta and Gozo (Portelli, 2016).

In 1960, Needlework was offered for the first time as a subject of specialisation for prospective teachers at the Mater Admirabilis Training College for Women Teachers as earlier, subject teachers had little or no formal training. The college had a fully equipped Needlework room where prospective teachers conducted practical work which was an indispensable part of the pedagogy.

On the introduction of 'Secondary Education for all' in 1970, Needlework was introduced as a compulsory subject for all girls in the first two years of secondary school, together with Home Economics. This required all schools to have subject rooms and more qualified subject teachers. All girls secondary schools had Needlework rooms with a similar layout, depending on the size and the location of the school. Needlework was also offered as an Option subject to the upper forms (Form $3 /$ Year 9). When vocationally-oriented Trade Schools were established in 1973, Needlecraft was one of the subject offered for girls. It included dress-cutting, millinery, sewing and related craft. The subject remained popular among students during these years, and its status remained high.

In 1981, there was a drastic change in Maltese state schooling. The education authorities abandoned comprehensive schooling and re-introduced a tiered education system, which differentiated students according to ability. This brought about a change in the curriculum of all schools, and certain subjects that were considered less academic were given secondary importance. The education authorities decided not to include Needlework, by now referred to as Needlecraft, among the compulsory subjects in the first two years of the girls' secondary schools. The reason for the removal of the subject from the list of compulsory subjects was to provide a similar curriculum for boys and girls in a drive for equal opportunities in education. At the time, boys were not taught Needlecraft (Portelli, 2016). After two years, the subject featured once again on the curriculum of the lower forms, sharing the time-slot on the timetable with Art and alternating between the subjects from week to week. Hence, students were following half the content of the previous curriculum.

Needlecraft was offered as an option in Form 3/Year 7 for all girls in secondary schools and the newly established junior lyceums, which catered form the more academically oriented students. The subject was not popular among the latter type of students, who were motivated to further their studies beyond secondary education (Portelli, 2016). Groups were small and the subject experienced a decline in popularity and in status the following two decades.

The utilitarian value of Needlecraft experienced a constant decline starting in the 1980s. As socioeconomic conditions changed, priorities changed too, and policymakers did not give Needlework the importance it previously enjoyed. Students opted for other subjects, and the decline was reflected in the dwindling numbers of candidates sitting for the national school-leaving examination in the subject (see Portelli, 2016).

The decline in status of Needlecraft was due to a number of factors, namely the changes in the socioeconomic conditions of the country, changes in governmental and educational policies, the expectations of teachers, students and parents, who influence their children's subject choices at lower levels. These factors brought about changes in attitude that had an impact on the subject's curriculum. Furthermore, the practical nature of the subject, the lack of interest by young adolescents to carry out practical work, and the large number of subjects available as options in secondary schools were also considered influential in the decline of the popularity of Needlework.

Another setback for the subject was the new policy introduced in 1990 by the government following the Education Act of 1988, on equal education opportunities for both sexes. Despite the potential 
breakthrough, this policy could have had for Needlework, the subject remained solely available for girls, and male students showed little interest in the subject which was perceived as a 'girls' subject'.

In 2012, the Ministry of Education and Employment launched a document entitled $A$ National Curriculum Framework for All (NCF) (Ministry of Education and Employment, December 2012). One of the key aims of the NCF, which was implemented as from September 2013, was to prepare students to acquire the necessary competencies to help them become lifelong learners, responsible citizens and to find employment. The latter aspect was a significant innovation in the Maltese education system. A number of changes were brought about in secondary schools with the implementation of the NCF with respect to gender and equality. The introduction of co-education in all state schools in September 2014 brought about changes in option choices. Textiles Studies, along with other subjects, was no longer offered to students going into Form I/Year 7 . Moreover, since the NCF provided a similar curriculum for all Form III/Year 9 students, common option choices were offered to all, without any gender discrimination. Consequently, from scholastic year 2014-15, boys interested in studying Textiles Studies were technically able to opt for it. However, in a letter circular published by the Department of Curriculum Management, it was pointed out that Heads of secondary schools were to inform their students that certain subjects/options might not be available if they were not already offered in their school or if very few students applied for them (Portelli, 2016). This was a setback for those boys who were interested in studying Textiles Studies, especially for those who had already been attending an all-boys secondary school. This means that Textiles Studies, one of the very few subjects, if not the only one, that is not always available as an option for boys, as so far the subject has never been taught in most schools. Whether a subject or an option is offered in a particular school is at the discretion of the Heads of School and the respective College Principals, irrespective of availability. Both teachers and students who opt for Textiles Studies stand to gain if school administrators decide to offer the subject. During the scholastic year 2017-18, there was only two male student studying Textiles Studies in secondary schools.

\section{ATTEMPTS AT REBRANDING THE SUBJECT}

As can be seen from the historical overview given above, the status of Textiles Studies has been on the decline for decades. Along the years, various attempts have been made to improve its image and remove its stigma as a merely domestic subject. For this reason, the content of the syllabus underwent important changes. However, in spite of all the efforts made by the Education Officer, Heads of Department and teachers, the number of students opting for the subject continued to decrease (Portelli, 2016).

The rebranding process began in 1997, when the subject's name changed to Textiles Studies. This was followed by considerable changes made to the Textiles Studies curriculum to improve the subject's value and make it more relevant to modern-day students.

An appropriate process of rebranding may be part of the solution to dispel the misconceptions that are frequently associated with Textiles Studies. In Malta, studies related to definitions, perceptions and change in name in school subjects have not be published yet. However, undergraduate research at the University of Malta carried out in the past shed light on the perception of Home Economics by a sample of Maltese adolescents and adults. Home Economics has similar problems of status in schools due to its origins as a domestic subject, so a parallel could be easily drawn with Textiles Studies. Gerada (2009) found that during the first decade of the 21st century, the perception of the Maltese towards Home Economics did not change much, and included a high degree of misinformation and many misconceptions. Moreover, the results showed that the public still maintained the traditional stereotypical image of the subject. Another study conducted by Pearson (2015) confirms Gerada's conclusions that people are misinformed about these subjects. Pearson's study on the perception of adolescents towards Textiles Studies revealed that adolescents who never studied Textiles Studies found it to be 'boring, irrelevant and useless' ( $p$. 77) as they were never given a clear idea of the subject's content. These adolescents also viewed the subject to be highly gendered and limited to gaining sewing skills. Also new subjects were constantly pushing their way into the secondary school curriculum, possibly also offering more attractive career prospects. Consequently, Textiles Studies still struggled for survival in search of a new value. The findings of Pearson's study highlight the general negative stigma that was associated with Textiles Studies, a situation that required deep re-thinking for Textiles Studies to improve its image and keep its place in the Maltese school curriculum.

Rebranding can be of benefit to the discipline mainly in two ways. On one hand, it allows a subject to acquire a new identity. On the other, it allows it to reach its professional goals through renewed 
content and pedagogies, to ensure that the knowledge and skills acquired by others are transferable and relevant for future generations (Malokwu, 2010; Malokwu and Kembe, 2012). The research conducted by Pearson was carried out while a reform in the Maltese educations system was taking place in schools, so it helped planners to identify the problems and devise a strategy to pinpoint solutions.

\section{IMMINENT REBRANDING PROCESS - THE VOCATIONAL ROUTE}

The landmark policy documents Learning Outcomes Framework (2015) and My Journey - Achieving through different paths (2016) brought about very significant reforms in the structure of the Maltese educational system. The policy set out in the latter document aimed to facilitate the introduction of a more equitable quality education within secondary schools. As from 2019, this new model shall offer applied and vocational learning programmes as optional school subjects alongside the compulsory core subjects, with the intention of enabling students to reach their full potential. This reform required considerable investment in preparation for its implementation phase.

In 2015, the Ministry of Education and Employment embarked on an EU co-funded project to complement the NCF, for curriculum experts to develop 'Learning Outcomes Framework' and 'Learning and Assessment' programmes for the different year groups. It was decided that Textiles Studies in schools should be replaced by a vocational subject with the aim of attracting more students and providing a different career pathway for those opting for it. Vocational subjects help students prepare for the labour market by providing them with the proper skills and competencies (Edexcel, 2010). This was a sudden and unexpected change for the Textiles Studies community, as there was no indication of such a change in the Directorate's policy. It will be a sad end for a subject with such a long curriculum history.

The learning outcomes for the new vocational subject, named Textiles and Fashion, were published by the Ministry of Education and Employment in 2016. However, they have yet to be implemented in schools, as the outgoing subject Textiles Studies has not yet been phased out from the education system. Some of the new vocational subjects are still in the pipeline. Textiles and Fashion shall be introduced for secondary school students as an option for Form 3/Year 9 as from September 2019, together with other three new vocational subjects. In order to reflect its scope, the learning outcomes for Textiles and Fashion were written in such a way as to redirect the subject content from an academic focus towards a more vocational/career-oriented one.

\section{A NEW CURRICULUM - VET TEXTILES AND FASHION}

The local school-leaving examination board, MATSEC, is currently designing two curricula for Textiles and Fashion, one at SEC level and another one for the Secondary Education Applied Curriculum (SEAC). The SEC level curriculum is a stand-alone qualification which the student may apply to sit for along with other SEC subjects. SEAC is a comprehensive certificate that secondary school students may obtain which includes individual subjects at applied level. A team of experts has been appointed to write the content and the learning outcomes of these curricula for their implementation in secondary schools. These will replace the current secondary school Textiles Studies curriculum and the one for SEC Textiles and Design, as the subject is called for SEC purposes. The aim of the of the Learning Outcomes Framework and Learning and Assessment Programmes for VET Textiles and Fashion was to 'stimulate and enhance the creative ability of students, to develop their entrepreneurial skills and to provide pathways into further education or employment in area related to fashion and textiles. [...] to develop the knowledge, skills, understanding, attitudes and competencies required by this industry' (Portelli, 2013, p. 1).

The team of experts currently working on the new curricula, of which I form part, is facing various challenges. We have to ensure that the syllabi have a specifically vocational slant rather than being academically-oriented. We have to consider the depth of knowledge required by the students, the inclusion of specific areas from the previous Textiles Studies syllabus and the availability of education resources for teachers. These syllabi are intended to facilitate the development of the artistic and creative talents of students, in such a way as to allow the latter to apply them to various areas, both within and outside the field of textiles and fashion. Students should acquire the competencies that are required by small and medium-sized companies from their workforce, in order to improve their job prospects. Employability is a key issue for students when choosing which optional school subjects to study in secondary school (Portelli, 2016). The whole rebranding process aims to attract more 
students of both genders to the area of Textiles and Fashion by providing the right environment to encourage a positive and interesting experience which would be useful for their future careers. The syllabi are being designed to be gender neutral and without any cultural bias, also keeping in mind the international cohort of students attending Maltese schools.

In order to teach this new 'rebranded' subject, suitable resources need to be made available. The syllabi are being designed with the assumption that all the schools where VET Textiles and Fashion is offered to students shall be provided with suitable fashion studios and with all the necessary equipment. For example, the new topic of fashion design, which has been included in order to instil and develop further the artistic talents of the students, cannot be taught without appropriate fashiondesign and pattern-making software. Computer Aided Design (CAD) and Computer Aided Manufacture (CAM) software shall allow students to gain familiarity with the latest technologies used in the fashion industry.

In the coming months, a campaign shall be launched among secondary school students and their parents to promote Textiles and Fashion as a vocational subject that is worth choosing. It shall highlight the employability potential and the exciting opportunities that exist in the various sectors of the corresponding industry, as well as the opportunity for further studies at post-secondary and tertiary level in the field. The campaign shall be organised by the Education Officer responsible for the subject in state schools, university academics and lecturers from the Malta College of Arts, Science and Technology. It shall strive to highlight the relevance of the subject in a way that can attract adolescents to this vocational discipline.

\section{NEW CHALLENGES FOR SUBJECT TEACHERS}

The number of Textiles Studies teachers in Malta is very small. There are currently about fifteen teachers in state secondary schools and only one teacher in a Catholic school. There are no teachers in independent private schools. The significant changes to the curricula require these educators to undergo retraining in order to acquire the appropriate pedagogies and to obtain an official qualification in vocational teaching. For this reason, the Faculty of Education of the University of Malta originally intended to design a post-graduate certificate course. However, in order to combine the required retraining with the attainment of a higher qualification, it was later decided to organise a three year, part-time evening MA degree in Vocational Education with various specialisations. The post-graduate degree course is organised in such a way that it gives the teachers flexibility to choose the qualification they would like to obtain. They can stop at the end of the first year and obtain a postgraduate certificate, leave after the second year with a post-graduate diploma, or do a third year for an MA degree. This flexibility was needed to encourage enrolment and to ensure that a sufficient number of teachers take up the challenge of teaching vocational subjects instead of choosing to teach a different academically-oriented subject. In order to further entice the teachers, the Ministry of Education agreed to cover all the first-year tuition fees for all participating teachers.

Initially, some Textiles Studies teachers were unaware of the changes that were taking place in their field. This was due to the fact that the Learning Outcomes Framework and Learning and Assessment Programmes for VET Textiles and Fashion were not yet introduced in schools, although they were published on the Ministry of Education and Employment website and were also subject to a consultation process with all stakeholders. Some of the teachers were reluctant to teach a vocational subject, as this requires a completely new approach in pedagogy and assessment, as well as the production of new teaching resources. Although the cohort of Textiles Studies teachers is young, some find it challenging to accept the shift in focus from an academic to a vocational orientation. This could be clearly observed during an information meeting that was held for prospective MA candidates. Some of subject teachers did not attend this meeting even though they were invited personally by me as the person responsible for the Textiles and Fashion stream of the MA in Vocational Education.

In order to overcome the initial scepticism of the teachers, I contacted them individually to explain the importance of retraining, as it was going to be difficult for them to be able to teach VET Textiles and Fashion without the required training. Some teachers were not easily convinced, and I had to meet them to explain further the relevance of the MA to their career as future Textiles and Fashion teachers. The degree was also presented as an opportunity to obtain further qualifications that enhance their career prospects. In some cases, individual teachers had difficulties related to their personal and family commitments and decided that it was impossible for them to take on part-time studies in the evening. 
Recruitment of prospective MA students was also hindered by the planned establishment of a corresponding MA in Vocational Education by the Institute for Education, within the Ministry of Education and Employment. The course is intended to run parallel to the one organised by the University, and shall be officially accredited by the National Commission for Further and Higher Education. Although this course has not yet been launched, some teachers opted to wait and decide on their options at a later stage.

\section{CONCLUSIONS}

There are eight teachers currently reading for the MA degree with a specialisation in Textiles and Fashion. The number is satisfactory and augurs well for the start of a new era in the teaching of textiles-related subjects to cohorts of students with an interest in pursuing a career in a related field. The introduction of fashion, both in the name and in the content of the subject, should prove very beneficial, since it is very popular with youths of both sexes and constitutes a very concrete career path in production, retail, marketing and advertising. Textiles and Fashion is not merely a rebranding exercise, but an answer to the needs and interests of a significant portion of students seeking a career in an economic sector that is expanding rapidly and that requires an adequately trained workforce, both in Malta and abroad. It is hoped that this watershed moment for textiles-related education will also bring about a shift in status that will give the subject a firm standing in the school curriculum, attracting enthusiastic teachers and students who will take full advantage of what Textiles and Fashion has to offer.

\section{REFERENCES}

[1] L. Portelli, Domestic Subjects in Malta. University of Malta: Unpublished M.Ed Dissertation, 1996.

[2] L. Portelli, "The Socioeconomic Factors in the Teaching of Needlecraft in 19th Century Malta," Family and Consumer Science Research Journal. A Centennial Special: History and Global Issues, vol. 38, no. 2, pp. 134-141. 2009.

[3] A. Yoxall, A History of the Teaching of Domestic Economy. Bath: Cedric Chivers, 1965.

[4] L. Portelli, Home Economics and Textiles Studies in Malta: a curriculum history 1960-2010. Unpublished Doctoral Thesis. UK: University of Brighton, 2016.

[5] Ministry of Education and Employment, A National Curriculum Framework for All. Malta: Ministry for Education and Employment, 2012.

[6] G. Gerada, Definitions and Perceptions of Home Economics in Malta: Focus On the Public and Academic Spheres. Unpublished Bachelor of Education dissertation. University of Malta, 2009.

[7] M. Pearson, The Perception of Adolescents towards Textiles Studies Education and related Careers in Malta. Unpublished Bachelor of Education Dissertation. Malta: University of Malta. 2015.

[8] N. Malokwu, The Challenges of Reducing Poverty in Nigeria: Repositioning Home Economics for Sustainable Education. Available at: www.educationforsustainabledevelopment.org. [Accessed 20 August 2018], 2010.

[9] N. Malokwu and E. M. Kembe, Food security, street food and family insecurity in Nigeria: Repositioning Home Economics in the 21 $1^{\text {st }}$ Century. In: D. Pendergast, SS. McGregor, and K. Turkki, eds. Creating Home Economics Futures: The next 100 years. Australia: Australian Academic Press, 2010.

[10] Directorate for Quality and Standards in Education, Learning Outcomes Framework. Malta: Ministry for Education and Employment, 2015.

[11] Ministry of Education and Employment, My Journey - Achieving through different paths. Malta: Ministry for Education and Employment, 2016.

[12] Edexcel, Introduction to BTEC. London: Pearson Publishers, 2010.

[13] L. Portelli, Textiles and Fashion - Local Curriculum Development Experts. Unpublished position paper, 2013. 